\title{
Long-term modulation of learning following locus coeruleus stimulation: Behavioral and neurochemical data
}

\author{
JEANNE VELLY \\ Institut de Pharmacologie, Strasbourg, France \\ ELIANE KEMPF \\ Centre de Neurochimie du CNRS, Strasbourg, France
}

and

\author{
BERNARD CARDO and LYDIA VELLEY
}

Université de Bordeaux I, Talence, France

\begin{abstract}
This paper summarizes some behavioral and neurochemical data relating to the delayed effect of locus coeruleus stimulation on the learning capabilities of the rat. The first observation showed that electrical stimulation of the locus coeruleus of a 15-day-old rat improved the acquisition and extinction of a food-reinforced operant task performed 4 weeks later. The neurochemical lesion of the dorsal noradrenergic bundle, 10 days before the stimulation, did not decrease the behavioral effect, whereas the neurochemical lesion of the locus coeruleus proper suppressed the improvement. Furthermore, we studied the long-term effect of the stimulation on some biochemical parameters of the coerulean system: First, the turnover of noradrenaline increased in the locus coeruleus 4 days after the stimulation, whereas it decreased 4 weeks after the treatment in the nucleus proper and in the hippocampus. Second, 4 weeks after the stimulation, the characteristics of some adrenoceptor populations were significantly changed, in particular regions of the brain. The number of $\alpha_{2}$-adrenoceptors was increased in the cortex, the hippocampus, and particularly the hypothalamus. The number of $\alpha_{1}$-adrenoceptors was increased in the cortex. Neither the number nor the affinity of $\beta$ receptors was altered by the stimulation. Likewise, the number of $\alpha_{1^{-}}, \alpha_{2^{-}}$, and $\beta$-adrenoceptors in the brainstem was not changed. These results are discussed. To explain our behavioral data, we assume that the performance improvement in prestimulated rats is due, for the most part, to a reduced reaction to stressful situations. On this basis, the stressreduction hypothesis is tentatively related to the binding data showing that the most significant increase of the $\alpha_{2}$-receptors was observed in the hypothalamus.
\end{abstract}

In previous studies, we showed that electrical stimulation of the lateral hypothalamus of 15-day-old rats significantly enhanced the learning of various tasks examined 4 weeks later. We first demonstrated that this stimulation improved the acquisition and extinction of a foodreinforced task (Velley \& Cardo, 1977). In subsequent experiments, we observed the same effect on the acquisition and reversal of a light-dark discrimination, whether appetitively or aversively reinforced, as well as on the acquisition of a one-way avoidance task (Velley, Chassaing, \& Cardo, 1981).

This article is based on a roundtable discussion held at the European Brain and Behavior Society Workshop on Brain Plasticity, Learning and Memory held August 30-September 1, 1984, in Strasbourg, France.

This work was supported by the INSERM (Grant 82.6.017), the DGRST (Grant 82.J.1428), and partially by the CNRS (U.A. 339). We thank S. Sara for helpful comments on the manuscript. Correspondence should be addressed to L. Velley, Laboratoire de Psychophysiologie, Université de Bordeaux, avenue des Facultés, 33405 Talence, France.
The next step in these investigations was to determine whether the same improvement could be obtained after stimulation of other brain regions, or if the phenomenon was limited to the lateral hypothalamus. We found that such an increase in learning ability was dependent on the site of stimulation. Stimulation of the parietal cortex, the nucleus accumbens, or the substantia nigra had no effect on learning, but stimulation of the nucleus locus coeruleus (LC) produced the same improvement as stimulation of the lateral hypothalamus (Velley \& Cardo, 1979). The aim of the experiments summarized below was to examine further the role of the LC in these behavioral effects.

\section{STIMULATION STUDIES}

Detailed descriptions of the methods used have been published elsewhere (Velley \& Cardo, 1977, 1979; Velley, Cardo, \& Bockaert, 1981; Velley, Nassif, Kempf, \& Cardo, 1983). In all experiments, male SpragueDawley rats were used. Stimulation electrodes were 
bilaterally implanted in the LC under stereotaxic control when the rats were 13 days of age. Each electrode consisted of two twisted platinum-iridium wires, $0.09 \mathrm{~mm}$ in diameter. Stimulation was applied on Days 15 and 16, in 15-min sessions separated by an interval of $30 \mathrm{~min}$. The stimulation parameters were as follows: stimulations per hour, 2,580; duration, $200 \mathrm{msec}$; sinusoidal current, $100 \mathrm{~Hz}, 60 \mu \mathrm{A}$ (peak to peak). Each rat was stimulated for a total of $4 \mathrm{~h}, 2 \mathrm{~h}$ on Day 15 and $2 \mathrm{~h}$ on Day 16. The electrodes were removed 1 day later under light anesthesia. Three groups of rats were used: stimulated rats (S), implanted but not stimulated rats (I), and nonimplanted rats $(\mathrm{C})$.
Figure 1 summarizes the results of LC stimulation on the acquisition and extinction of a food-reinforced Skinnerian task performed 4 weeks later (Velley, 1983). For the acquisition session (A), each rat was placed in the test chamber for $1 \mathrm{~h}$ on a continuous reinforcement schedule (CRF) without previous training or shaping. Two measures of the animal's performance were taken: the number of leverpresses per 5-min interval (A) and the latency (in sec) to obtain the 10th pellet (B). The rats underwent one 15-min session daily until their performance reached at least 25 responses $/ 5 \mathrm{~min}$. The last session was followed $24 \mathrm{~h}$ later by a 30 -min extinction session immediately after a 5-min session with reinforcement (C). All behavioral

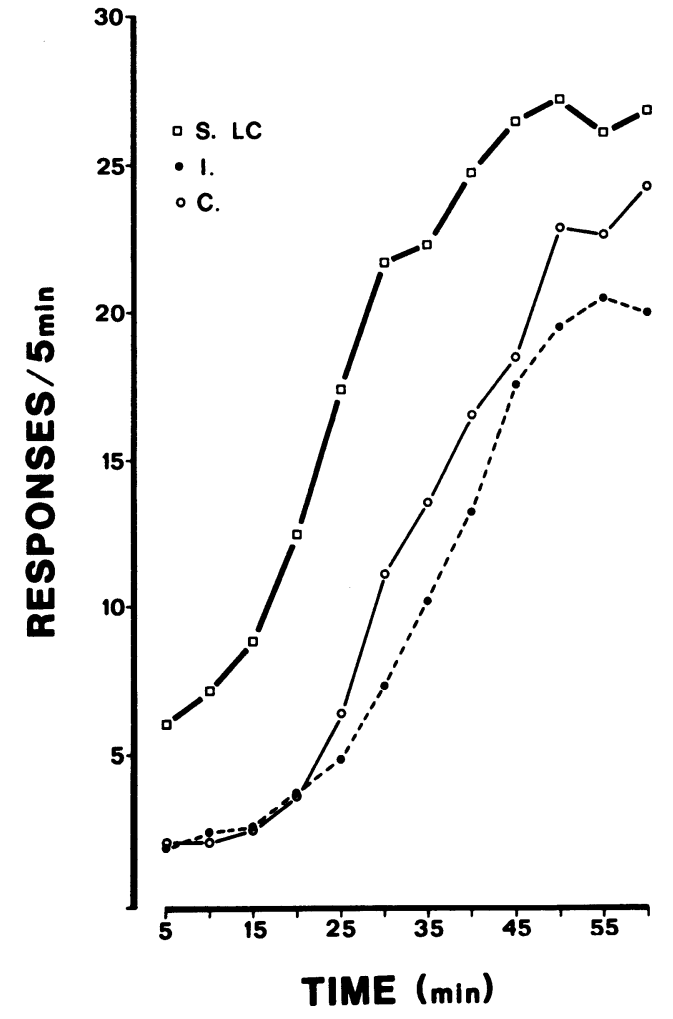

A

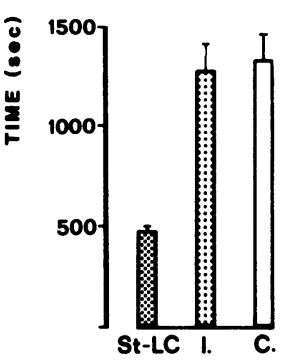

B

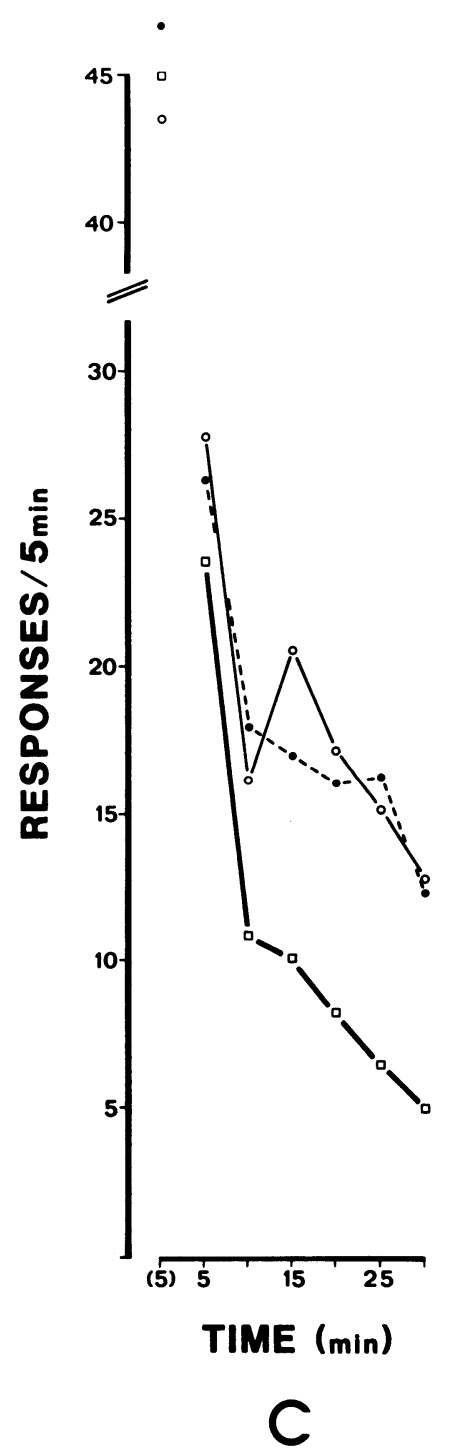

Figure 1. Effects of LC stimulation at 15 and 16 days of age on the acquisition and extinction of a CRF task performed 4 weeks later. (A) Acquisition curves of $S . L C(N=20), I(N=18)$, and $C(N=20)$ rats during the 1-h session (I vs. C, n.s.; S vs. I, p < .0001). (B) Mean latencies of the 10th response in acquisition (I vs. C, n.s.; S vs. I, p < .001). (C) Extinction curves of $\mathrm{S} . \mathrm{LC}(\mathrm{N}=8), \mathrm{I}(\mathrm{N}=10), \mathrm{C}(\mathrm{N}=10)$ rats. (5) indicates a 5-min session with reinforcement before the extinction session (S vs. I, vs. C, n.s.). For the extinction curves, I vs. C, n.s.; S.LC vs. I, p $<.0001$. S.LC = rats stimulated in the $L C ; I=$ rats implanted but not stimulated; $C=$ nonimplanted rats. 
tests were conducted blind. In all experiments, the $t$ test and analysis of variance with repeated measures were used to analyze the data.

These results showed that the stimulation of the LC 4 weeks prior to the task produces a significant improvement of performance in the acquisition of an appetitively reinforced CRF task.

This enhancement appeared at the beginning of acquisition, as shown by the difference in the number of responses during the first $5 \mathrm{~min}$ of the test (Figure 1A) and by the difference in the mean latencies for the 10th pellet (Figure 1B). Extinction in $\mathrm{S}$ rats was also more rapid than that of the two other groups, in spite of the fact that during the first 5 min with continuous reinforce- ment the performance of the three groups was not significantly different.

\section{LESION EXPERIMENTS}

The findings in our stimulation studies strongly suggested that the LC system plays an important part in the behavioral effects observed. However, given the widespread projections of the LC (Lindvall \& Björklund, 1974; Moore \& Bloom, 1979), the effects could be due either to a long-term pre- or postsynaptic modification in all the regions innervated by the nucleus, or to a modification located in a particular region of the brain. The largest ascending projection of the LC is the dorsal norad-

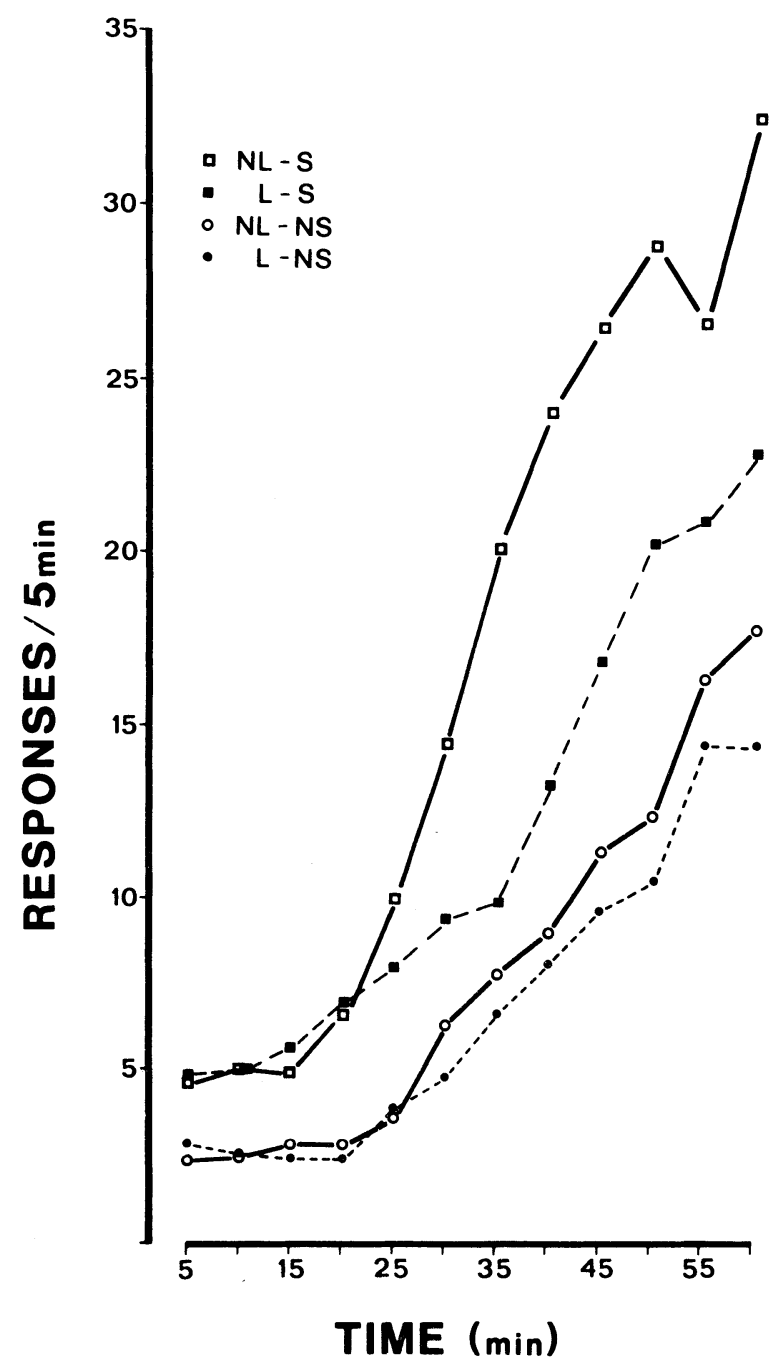

A

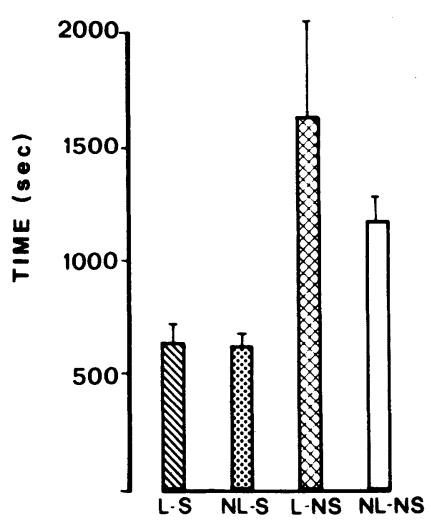

B

Figure 2. Effects of DNB lesion on the learning enhancement produced by LC stimulation. Number of rats: NL-S, 8; L-NS, 8; L-S, 7; NL-NS, 8. (A) Acquisition curves for the four groups of rats (statistical significance: NL-S vs. NL-NS, $p<.002$; L-NS vs. NL-NS, n.s.; L-S vs. NL-S, p < .05). (B) Mean latencies of the 10 th response (L-S vs. NL-S, n.s.; L-S vs. NL-NS, $p<.001$ ). 
renergic bundle (DNB). Consequently, in our first experiment, the DNB of 25-day-old rats was bilaterally destroyed at the level of mesencephalon by local injections of 6-hydroxydopamine ( $4 \mu \mathrm{g}$ in $2 \mu \mathrm{l}$ on each side). During the same operation, two electrodes were bilaterally implanted in the LC. The stimulation was applied 8 days later. As in previous experiments, the acquisition of the operant task took place 4 weeks later. Four groups of rats were included: unlesioned and stimulated (NL-S), lesioned and stimulated (L-S), unlesioned and nonstimulated (NLNS), and lesioned and nonstimulated (L-NS).

As shown in Figure 2, acquisition was fastest in the NL$S$ group. The performance of the L-NS group was the same as that of the NL-NS group. The overall performance of the L-S rats was significantly lower than that of the NL-S rats (A), but better than that of the L-NS and NL-NS groups. However, during the first 20 min of acquisition, the response rates of the NL-S and L-S groups

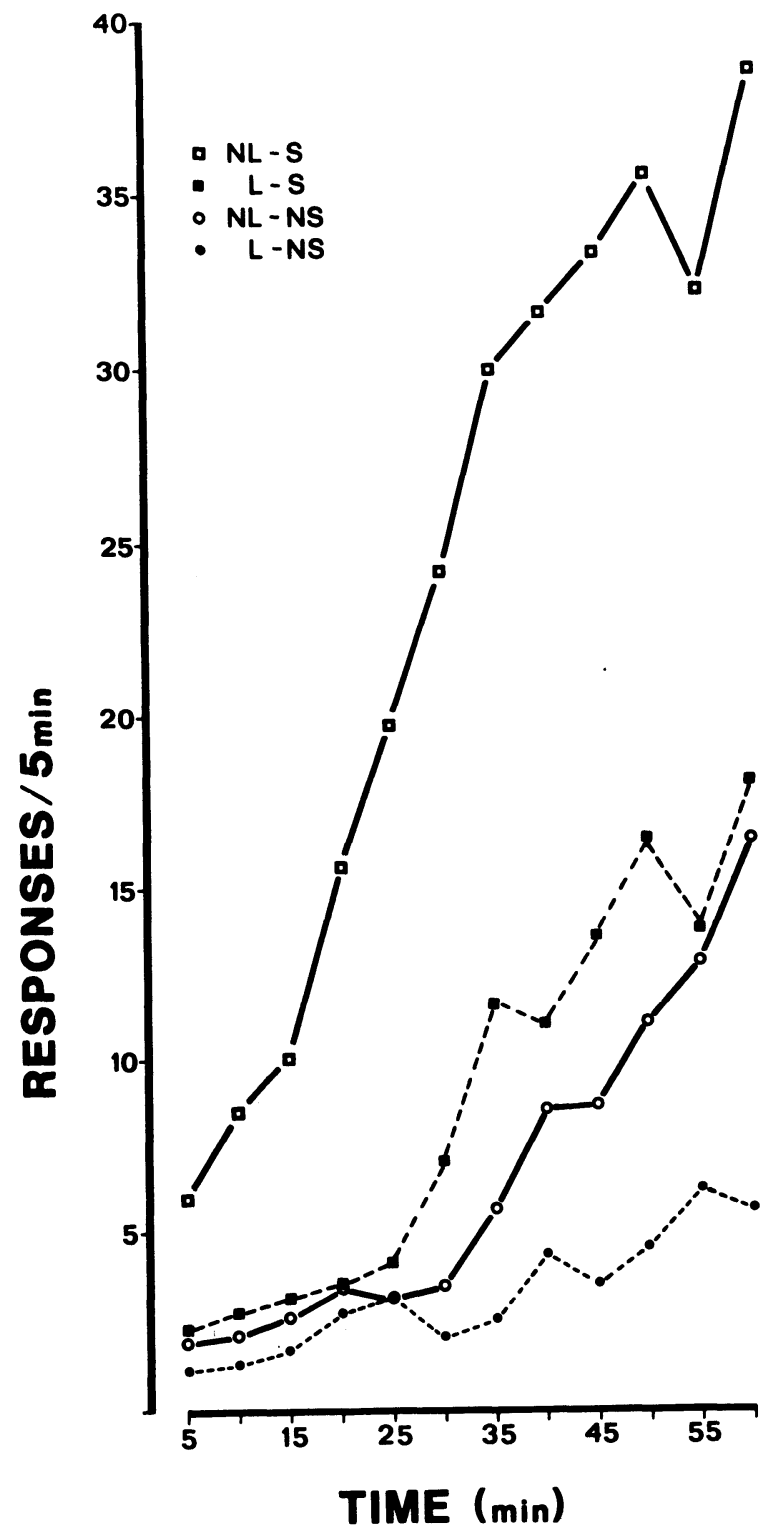

A

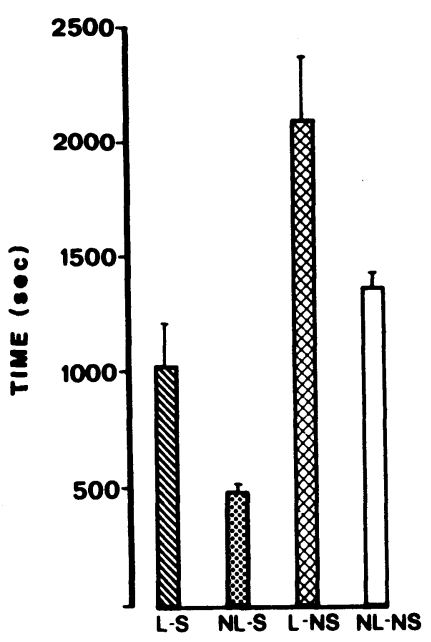

B

Figure 3. Effects of a LC lesion on the learning enhancement produced by the stimulation of the LC region. Number of rats: NL-S, 7; L-S, 9; NL-NS, 8; L-NS, 10. (A) Acquisition curves for the four groups of rats (statistical significance: NL-S vs. NL-NS, p < .001; L-NS vs. NL-NS, n.s.; L-S vs. NLS, p < .001; L-S vs. L-NS, p < .02). (B) Mean latencies of the 10th response (NL-S vs. NL-NS, p < .01; L-NS vs. NL-NS, $p=.05 ;$ L-S vs. NL-S, $p<.001$; L-S vs. L-NS, p $<.01$ ). 
were the same and the mean latency of the 10th response was not different in the two groups (B).

The residual content of noradrenaline (NA) in the hippocampus and cortex of the rats of the two lesioned groups varied between $1.1 \%$ and $3.1 \%$. Taken together, these data showed that lesions of the DNB do not have a clear and consistent effect, since the main effect of the stimulation, that is, the enhancement of performance at the beginning of the acquisition, was not disturbed by the DNB lesion.

Consequently, in another experiment, we lesioned the LC proper by local injection of 6-hydroxydopamine (4 $\mu \mathrm{g}$ in $1 \mu \mathrm{l}$ on each side). Two weeks later, the stimulation electrodes were implanted in the region of the LC. All the other aspects of the experiment (stimulation and behavioral testing) were the same as in the first experiment. Likewise, four groups of rats were used: L-S, NL-S, LNS, and NL-NS.

The results of the acquisition session are summarized in Figure 3. Stimulation alone again produced a significant improvement in performance. However, in contrast with the small effect of the DNB lesion, the destruction of the LC proper without stimulation (L-NS group) produced very poor performance during the acquisition session. The overall performance of the L-S group was significantly better than the performance of the L-NS group. The residual content of NA after neurochemical lesion of the LC was measured in the hippocampus, the cortex, and the brainstem.

Although the loss of NA in the three structures was relatively small compared with that found after DNB lesions, the differences between the NA content of the control group (NL-NS) and of the two lesioned groups (L-NS and L-S) were significant (percentage of control: cortex, $37.2 \%$; hippocampus, $60 \%$; brainstem, $72.3 \%$ ).

In conclusion, these results suggest that the LC system is involved in the long-term effect of the stimulation, but that the rostral projections passing through the dorsal bundle, in front of the lesion, are not critically involved in the observed effect (Velley et al., 1983).

\section{BIOCHEMICAL STUDIES}

\section{Alteration of the NA Turnover After Stimulation of the LC}

Given the biochemical homogeneity of the coerulean system, we attempted to find some long-term neurochemical modifications that might eventually be found to be related to the behavioral effects. To this end, we stimulated the LC in exactly the same conditions as for the behavioral experiments and examined NA levels and turnover in the cortex, hippocampus, and LC 4 days and 4 weeks after the stimulation.

Levels of NA in the three structures studied were not modified either 4 days or 4 weeks after the stimulation. However, 4 days after the stimulation, the turnover of NA was significantly increased in the LC but not in the hippocampus or in the cortex (Table 1). This observation was confirmed by another experiment, which showed that, at this time, tyrosine hydroxylase activity was increased by $48 \%$ in the LC.

In contrast, 4 weeks after the stimulation, a significant decrease of the NA turnover was observed in the LC and in the hippocampus (Table 2) (Velley, 1983).

\section{Modulation of Rat Brain $\alpha$-Adrenoceptor Populations After Stimulation of the LC}

The aim of these experiments was to find out whether adrenergic receptors were involved in some way in the long-lasting behavioral modification. In the first experiment, we investigated the characteristics of the $\alpha_{1^{-}}, \alpha_{2^{-}}$, and $\beta$-adrenergic receptors of the cerebral cortex 4 weeks after the stimulation (Velley, Cardo, \& Bockaert, 1981). No significant alteration in the number of $\beta$-receptors $\left(\left({ }^{3} \mathrm{H}\right)\right.$-dihydroalprenolol binding sites) was observed, although the stimulation produced a slight (14\%), but significant, increase in the number of $\alpha_{1}$-receptors $\left(\left({ }^{3} \mathrm{H}\right)\right.$ WB 4101 binding sites) as well as a rise (36\%) in the number of $\alpha_{2}$-receptors $\left(\left({ }^{3} \mathrm{H}\right)\right.$ clonidine binding sites).

To verify these biochemical data by a pharmacological approach, we compared the effects of clonidine injection on locomotor activity in $\mathrm{S}$ and control rats in the open-

Table 1

Regional Brain Noradrenaline Levels and Turnover in Nonstimulated and Stimulated Rats 4 Days After the Stimulation

\begin{tabular}{lccc}
\hline & $\begin{array}{c}\text { NA Steady-State } \\
\text { Level }\end{array}$ & $\begin{array}{c}\text { NA Decline } \\
\text { After } \alpha \mathrm{MpT}\end{array}$ & $\begin{array}{c}\text { Turnover } \\
\text { Rate }\end{array}$ \\
\hline Hippo- & (ng/g WW) & (Slope) & $(\mathrm{ng} / \mathrm{g} / \mathrm{h})$ \\
campus & S $212 \pm 27(8)$ & $0.092 \pm 0.029(16)$ & $45 \pm 15$ \\
Cortex & NS $156 \pm 19(8)$ & $0.164 \pm 0.029(16)$ & $59 \pm 12$ \\
& S $193 \pm 41(8)$ & $0.160 \pm 0.027(16)$ & $71 \pm 19$ \\
& (ng/LOCUS) & & (ng/LOCUS/h) \\
Locus & NS $4.51 \pm 1.06(8)$ & $0.076 \pm 0.030(16)$ & $0.78 \pm 0.35$ \\
Coeruleus & S $5.09 \pm 1.43(8)$ & $0.142 \pm 0.036(16)$ & $1.61 \pm 0.61$ \\
\hline
\end{tabular}

Note-Turnover parameters were determined by blocking the synthesis of $N A$ by intraperitoneal injection of $\alpha$-methyl-para-tyrosine $(\alpha M p T$, $300 \mathrm{mg} / \mathrm{kg}$ ). Regression lines were calculated from the least squares fit. NS and $S=$ nonstimulated and stimulated rats, respectively. Number of rats are given in parentheses. Values are given as means $\pm S D . \quad{ }^{*} p<.001$.

Table 2

Regional Brain Noradrenaline Level and Turnover in Nonstimulated and Stimulated Rats 28 days After the Stimulation

\begin{tabular}{lccc}
\hline & $\begin{array}{c}\text { NA Steady State } \\
\text { Level }\end{array}$ & $\begin{array}{c}\text { NA Decline } \\
\text { After } \alpha \mathrm{MpT}\end{array}$ & $\begin{array}{c}\text { Turnover } \\
\text { Rate }\end{array}$ \\
\hline Hippo- & NS $422 \pm 59(7)$ & $0.113 \pm 0.024(15)$ & $109 \pm 27$ \\
campus & S $358 \pm 21(8)$ & $0.034 \pm 0.018 *(16)$ & $28 \pm 15$ \\
Cortex & NS $246 \pm 31(7)$ & $0.131 \pm 0.029(15)$ & $74 \pm 18$ \\
& S $234 \pm 50(8)$ & $0.147 \pm 0.031(16)$ & $79 \pm 20$ \\
Locus & NS $9.83 \pm 1.45(7)$ & $0.109 \pm 0.027(15)$ & $2.46 \pm 0.70$ \\
Coeruleus & S $8.83 \pm 1.76(8)$ & $0.039 \pm 0.029 *(16)$ & $0.79 \pm 0.17$ \\
\hline
\end{tabular}

Note-For explanations see note to Table 1 . 
field test. To stimulate only the $\alpha_{2}$-adrenoceptors, very small doses of the drug were used $(1,2.5,5$, and $10 \mu \mathrm{g} / \mathrm{kg}$ ). In stimulated and control animals, the wellknown sedation produced by clonidine was the same, but only $\mathrm{S}$ rats exhibited a delayed hyperactivity, beginning $24 \mathrm{~h}$ after the injection. For the $5-\mu \mathrm{g} / \mathrm{kg}$ dose, this rebound of activity was still detectable 8 days after the injection. More recently, using the same procedure, we have demonstrated that this late hyperactivity was due to the activation of $\alpha_{1}$-adrenoceptors, as it was suppressed by prazosin, an $\alpha_{1}$-adrenoceptor antagonist (Velley, Kempf, \& Cardo, 1982). Although the binding data cannot be directly compared to the pharmacological results, taken together, these observations strongly suggest that the stimulation of the LC produces modifications of the adrenoceptor populations and, more importantly, that these modifications last at least 4 weeks. Thus, the possibility that the long-term behavioral effects were due, at least in part, to a modulation of $\alpha$-receptor populations cannot be excluded.

However, the binding data are not easy to reconcile with our behavioral results, summarized above (Figure 2), which showed that the neurochemical lesion of the DNB did not suppress the beneficial effect of the LC stimulation, in spite of a near-total noradrenergic depletion in the cortex. Thus, the rostral projections of the LC passing through the DNB are not critically involved in the behavioral improvement. Consequently, if we assume, with most of the authors (Unnerstall, Kopajtic, \& Kuhar, 1984; Palacios \& Wamsley, 1984), that, with few exceptions, regions that have $\alpha_{2}$-binding sites are innervated by noradrenaline neurons, the increase of the cortical $\alpha_{2}$ receptors observed after the stimulation is probably not implicated in the performance enhancement. This observation prompted us to study the long-term effect of LC stimulation (4 weeks) on the characteristics of the $\alpha_{1^{-}}$, $\alpha_{2^{-}}$, and $\beta$-adrenoceptors, not only in the cortex but also in the hippocampus, the hypothalamus, and the brainstem. The ligands used were: $\left({ }^{125} \mathrm{I}\right)$-iodocyanopindolol (ICYP) for $\beta$-adrenoceptors (Engel, Hoyer, Berthold, \& Wagner, $1981),\left({ }^{3} \mathrm{H}\right)$-prazosin for $\alpha_{1}$-adrenoceptors, and $\left({ }^{3} \mathrm{H}\right)$ yohimbine for the $\alpha_{2}$-adrenoceptors. The results shown in Table 3 allow the following observations:

In agreement with our previous data (Velley, Cardo, $\&$ Bockaert, 1981), no significant alteration in the number of $\beta$-binding sites was observed in the four structures analyzed. In the cortex, the number of $\alpha_{1-}$ and $\alpha_{2}$ receptors was significantly increased $(68 \%$ and $86 \%$, respectively), but the affinity was decreased (i.e., an increase of the $\mathrm{K}_{\mathrm{D}}$ ). In the hippocampus, only the $\alpha_{\mathbf{2}^{-}}$ adrenoceptor population was modified (increase of the $B_{\max }$ and of the $K_{D}$ ). In the hypothalamus, the increase of the $\alpha_{1}$-binding sites did not reach significance, but the affinity for this site was decreased. A great increase of the $\alpha_{2}$-adrenoceptors was observed in this area (113\%), associated with an affinity decrease. Lastly, no modification of the $\beta$-, $\alpha_{1^{-}}$, and $\alpha_{2}$-receptors was shown in the brainstem.

More recently, in order to get a better idea of the timecourse of the $\alpha$-adrenoceptor increase, we performed another binding experiment, in which the rats were killed 2 weeks after the LC stimulation, instead of after 4 weeks. After this interval, the number of $\alpha_{2}$-binding sites and the $\mathrm{K}_{\mathrm{D}}$ were significantly increased in the cortex and the hypothalamus, but not in the hippocampus. The number of $\alpha_{1}$-adrenoceptors and the $\mathrm{K}_{\mathrm{D}}$ were increased in the

Table 3

Characteristics of $\alpha_{1}-, \alpha_{2}$ - and $\beta$-Adrenergic Receptors in Various Regions of the Brain of Stimulated and Control Animals

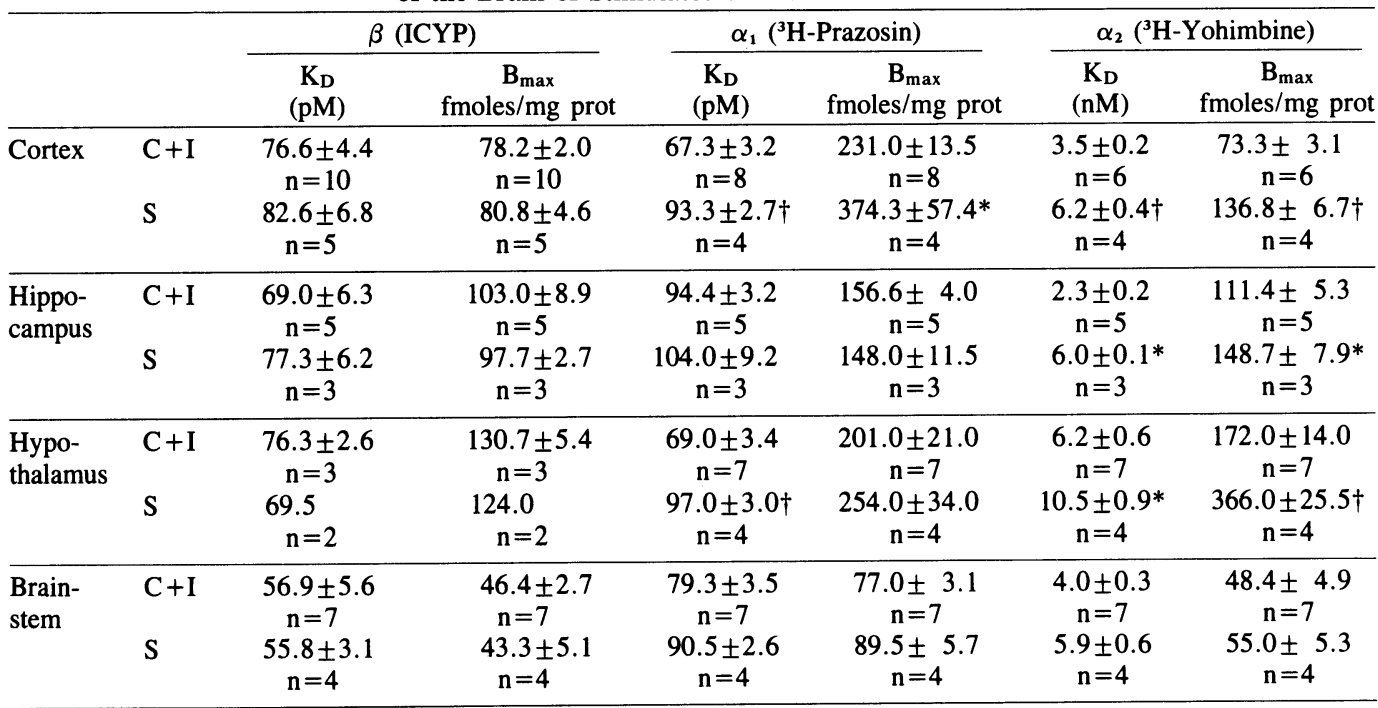

Note $-S$, stimulated rats; $C+I$, control + implanted rats; $n=$ number of experiments. $B_{\max }$ and $K_{D}$ are given as means \pm SEM. ${ }^{*} p<.01 . \dagger p<.001$. 
hypothalamus but not in the cortex. Thus, it seems that the supersensitivity of the adrenoceptor populations results from a slow process, since some of the modifications observed 4 weeks after the treatment had not yet appeared 2 weeks after stimulation.

\section{DISCUSSION}

Three main points emerge from the preceding data: (1) The stimulation of the LC produces, 4 weeks later, a significant improvement of performance in the acquisition and extinction of an appetitively reinforced operant task. (2) Although the neurochemical lesion of the LC proper suppresses this effect, it does not seem that the dorsal bundle projections of the LC are a critical factor in these behavioral effects. (3) The same stimulation applied under the same conditions induces biochemical modifications of the noradrenergic system, that is, a turnover decrease and a long-term increase of $\alpha_{2}$-receptors in the hypothalamus, the hippocampus, and the cortex, and of $\alpha_{1}$-receptors in the cortex.

Furthermore, the enhancement of performance in the prestimulated rats is probably not explained by a modification of the activity levels, since these rats were neither hyperactive nor hypoactive in an open-field test (Velley et al., 1982). Moreover, stimulation of the LC did not produce any modification of food consumption (Velley, 1983).

Some years ago, several theories postulated that the LC system was necessary, or was even the sole brain system responsible, for behavioral functions such as ingestive behavior, arousal, sleep, reinforcement, learning, and attention (see reviews in Amaral \& Sinnamon, 1977; Clark, 1979; McNaughton \& Mason, 1980). Two of these hypotheses, that is, the learning and attention hypotheses, might explain our data. Crow (1968) suggested that the LC system might play a role in learning, but, despite earlier reports (Anlezark, Crow, \& Greenway, 1973), more recent work has failed to confirm a noradrenergic component in the acquisition of many behavioral tasks (Amaral \& Foss, 1975; Heybach, Coover, \& Lints, 1978; Koob, Kelley, \& Mason, 1978; Roberts, Price, \& Fibiger, 1976; Sessions, Kant, \& Koob, 1976). The second theory that could explain our data is the attentional hypothesis proposed by Mason (see review in Mason \& Iversen, 1979). Using various tasks, Mason studied the behavior of rats in which the dorsal noradrenergic bundle was destroyed by 6-hydroxydopamine. His findings allowed him to suggest that this fiber system controls the capacity to ignore irrelevant stimuli in a normal rat. However, this attentional hypothesis was not supported by findings of the effects of dorsal bundle lesions (Owen, Boarder, Gray, \& Fillenz, 1982; Pisa \& Fibiger, 1980) or by studies on the effects of LC nucleus lesions (Crow, Deakin, File, Longden, \& Wendlandt, 1978). These negative data are in agreement with various observations showing that the LC system is not essential for complex behaviors. On the contrary, the anatomical organization and the physiolog- ical properties of this system predict a "modulatory" role. This general modulatory function can be analyzed in two slightly different ways.

First, numerous electrophysiological data suggest a role for the LC nucleus in the control of sensory inputs (Cedarbaum \& Aghajanian, 1978; Foote, Aston-Jones, \& Bloom, 1980; Segal \& Bloom, 1976; Woodward, Moises, Waterhouse, Hoffer, \& Freedman, 1979). Specifically, Segal and Bloom (1976) have proposed that the main function of the LC projection is to increase the signal-to-noise ratio. More recently, Aston-Jones and Bloom (1981) found, in awake rats, that LC neurons exhibit strong responses to environmental stimuli, and concluded that the LC system "may function to facilitate transition between behavioral states." It is noteworthy that, in our experiments, the enhanced performance of the stimulated rats was observed only during behavioral transitions: the enhancement was first seen at the beginning of the first learning session (Figure 1A). Likewise, after the removal of the reinforcement during the extinction session, the most significant decrease of responses of treated rats took place during the first $10 \mathrm{~min}$ of the session (Figure 1C). However, when the task was well learned, no difference between stimulated and control rats was observed (Figure 1C, first point of the abscissae). Thus, it seems that the behavioral enhancement appeared only when a parameter of the experimental situation was modified. If we suppose that the functioning of the LC is improved in stimulated rats, perhaps by the modification of the $\alpha$ adrenoceptor populations, we might say that at each transitional point in a learning situation the processing of novel stimuli will be more efficient in these rats than it will be in unstimulated control animals.

Another hypothesis that is consistent with our experimental data was clearly formulated by Amaral and Sinnamon (1977). Taking into account the anatomical and physiological similarities between the LC and the sympathetic ganglia, these authors proposed that a major function of the LC was to dampen the organism's response to stressors. This hypothesis is supported by the wellknown data on the reactivity of the LC system to stressful situations (Anisman, 1978; Stone, 1975; Tsuda et al., 1982; Weiss et al., 1981). For example, various observations have shown that novel stimuli and, more generally, all transitional states are stressful and produce an activation of the pituitary-adrenal axis.

The introduction of an animal into a new environment has been shown to induce an increase of corticosterone (Bassett \& Cairncross, 1973; File \& Peet, 1980; Pfister, 1979), as well as an increase of ACTH (Hennessy, Heybach, Vernicos, \& Levine, 1979). The same effect is observed after the omission of reinforcement during extinction (Coover, Goldman, \& Levine, 1971; Davis, Memmott, McFadden, \& Levine, 1976; Levine, Goldman, \& Cooper, 1972). Thus, given the fact that the enhanced performance in stimulated rats appeared only during the transitions between behavioral states, it is possible that these effects were due only to a reduced stress reac- 
tion, with a consequently better adaptation to a new experimental situation by the stimulated rats.

This stress-reduction hypothesis implies a major role for the hypothalamus. It is worth noting in this regard that our first behavioral data showing a long-term enhancement of performance were obtained after stimulation of the lateral hypothalamus (see introduction). This result suggests that the beneficial effect of the treatment involves some common process, whether the stimulation is applied in the lateral hypothalamus or in the LC. On this basis, the stress-reduction hypothesis may be tentatively related to the binding data summarized above, showing that the most significant increase of the $\alpha_{2}$-adrenoceptors was observed in the hypothalamus. Moreover, there is clear evidence that noradrenaline inhibits corticotrophin (ACTH) secretion by an action on the hypothalamus (see reviews in Amaral \& Sinnamon, 1977; Ganong, 1980; Jones et al., 1984), and it seems that the inhibition of the corticotrophin-releasing factor by noradrenaline is mediated by an $\alpha$-adrenoceptor mechanism (Buckingham \& Hodges, 1979; Ganong, 1980; Shimizu, 1984). Thus, it is conceivable that the increase in number of hypothalamic $\alpha_{2}$-receptors observed after stimulation of the LC modulates the noradrenergic control of the ACTH release.

To test this possibility more directly, we recently compared the reactivity of the pituitary-adrenal axis of stimulated and implanted rats immediately after each rat was introduced for the first time for $10 \mathrm{~min}$ in an open field. The first results showed that, although no behavioral difference was observed between the two groups, the increase of ACTH response of the stimulated rats to the stressful situation was significantly smaller than the increase found in implanted rats (basal levels of blood ACTH in $\mathrm{pg} / \mathrm{ml}: \mathrm{S}, 13 \pm 3$; I, $17 \pm 2$; blood levels of ACTH after $10 \mathrm{~min}$ of exposure in the open field in $\mathrm{pg} / \mathrm{ml}$ : $S, 133 \pm 13 ; \mathrm{I}, 415 \pm 67)$. Thus, the stress-reduction hypothesis cannot be excluded and requires confirmation.

In conclusion, the long-term behavioral effects of LC stimulation may be explained either by an improved ability to detect novel and significant stimuli or by a reduced reaction to the stress produced by the same stimuli. The data presently available do not allow us to choose between these two hypotheses. Furthermore, these two possibilities are perhaps not exclusive: the LC system appears to have diffuse and widespread projections with little regional specificity. The functions of this system may therefore be rather general. Consequently, it may be that the ability to detect novel stimuli and the reaction to stress are simultaneously modified by stimulation of the LC. This integrated hypothesis requires further investigation.

\section{REFERENCES}

Amaral, D. G., \& Foss, J. A. (1975). Locus coeruleus lesions and learning. Science, 188, 377-378.

Amaral, D. G., \& Sinnamon, H. M. (1977). The locus coeruleus: Neurobiology of a central noradrenergic nucleus. Progress in Neurobiology, 9, 147-196.

Anisman, H. (1978). Neurochemical changes elicited by stress. Behavioral correlates. In A. Anisman \& G. Bignami (Eds.), Psychopharmacology of aversively motivated behavior. New York: Plenum Press.
Anlezark, G. M., Crow, T. J., \& Greenway, A. P. (1973). Impaired learning and decreased cortical norepinephrine after bilateral locus coeruleus lesions. Science, 181, 682-684.

Aston-Jones, G., \& BLoom, F. E. (1981). Norepinephrine-containing locus coeruleus neurons in behaving rats exhibit pronounced responses to non-noxious environmental stimuli. Journal of Neuroscience, 1 , 887-900.

Bassett, J. R., \& Cairncross, K. D. (1973). Parameters of novelty, shock predictability and response contingency in corticosterone release in the rat. Physiology \& Behavior, 10, 901-907.

Buckingham, J. C., \& HodGes, J. R. (1979). Hypothalamic receptors influencing the secretion of corticotrophin releasing hormone in the rat. Journal of Physiology, 290, 421-431.

Cedarbaum, J. M., \& Aghajanian, C. K. (1978). Afferent projections to the rat locus coeruleus as determined by a retrograde tracing technique. Journal of Comparative Neurology, 178, 1-16.

CLARK, T. K. (1979). The locus coeruleus in behavioral regulation: Evidence for behavior-specific versus general involvement. Behavioral \& Neural Biology, 25, 271-300.

Coover, G. D., Goldman, L., \& Levine, S. (1971). Plasma corticosterone increases produced by extinction of operant behavior in rats. Physiology \& Behavior, 6, 261-263.

Crow, T. J. (1968). Cortical synapses and reinforcement: A hypothesis. Nature, 219, 736-737.

Crow, T. J., Deakin, J. F. W., File, S. E., Longden, A., \& WendLANDT, S. (1978). The locus coeruleus noradrenergic system. Evidence against a role in attention, habituation, anxiety and motor activity. Brain Research, 155, 249-261.

Davis, H., Memmott, J., McFadden, L., \& Levine, S. (1976). Pituitary-adrenal activity under different appetitive extinction procedures. Physiology \& Behavior, 17, 687-690.

Engel, G., Hoyer, D., Berthold, R., \& Wagner, H. (1981). (I) ${ }^{125}$ iodocyanopindolol, a new ligand for $\beta$-adrenoceptors: Identification and quantification of subclasses of $\beta$-adrenoceptors in the guinea pig. Naunyn-Schmiedeberg Archives of Pharmacology, 317, 277-285.

FILE, S. A., \& PEET, L. A. (1980). The sensitivity of the rat corticosterone response to environmental manipulations and to chronic chlordiazepoxyde treatment. Physiology \& Behavior, 25, 753-758.

Foote, S. L., Aston-Jones, G., \& Bloom, F. E. (1980). Impulse activity of locus coeruleus neurons in awake rats and monkeys is a function of sensory stimulation and arousal. Proceedings of the National Academy of Science (U.S.), 77, 3033-3037.

GANONG, W. F. (1980). Neurotransmitters and pituitary function: Regulation of ACTH secretion. Federation Proceedings, 39, 2923-2930.

Hennessy, M. B., Heybach, J. P., Vernicos, J., \& Levine, S. (1979). Plasma corticosterone concentrations sensitively reflect levels of stimulus intensity in the rat. Physiology \& Behavior, 22, 821-825.

Heybach, J. P., Coover, G. D., \& Lints, C. E. (1978). Behavioral effects of neurotoxic lesions of the ascending monoamine pathways in the rat brain. Journal of Comparative \& Physiological Psychology, 92, 58-70.

Jones, M. T., Gillham, B., Altoher, A. R. H., Nicholson, S. A., CAmpbell, E. A., Watts, S. M., \& Thody, A. (1984). Clinical and experimental studies on the role of GABA in the regulation of ACTH secretion: A review. Psychoneuroendocrinology, 9, 107-123.

Koob, G., Kelley, A. E., \& Mason, S. T. (1978). Locus coeruleus lesions: Learning and extinction. Physiology \& Behavior, 20, 709-716.

Levine, S., Goldman, L., \& Cooper, G. D. (1972). Expectancy and the pituitary-adrenal system. In Ciba Foundation Symposium (Vol. 8). Elsevier: Amsterdam.

LiNDVALL, O., \& BJöRKLUND, A. (1974). The organization of the ascending catecholamine neuron systems in the rat brain. Acta Physiologica Scandinavica, Supplement, 412, 1-48.

MASON, S. T., \& IVERSEN, S. D. (1979). Theories of the dorsal bundle extinction effect. Brain Research Reviews, 1, 107-137.

McNaughton, N., \& Mason, S. T. (1980). The neurophysiology and neuropharmacology of the dorsal ascending noradrenergic bundle: A review. Progress in Neurobiology, 14, 157-219.

Moore, R. Y., \& Bloom, F. E. (1979). Central catecholamine neuron systems: Anatomy and physiology of the norepinephrine and epinephrine systems. Annual Review of Neuroscience, 2, 113-168. Owen, S. R., Boarder, M. R., Gray, J. A., \& Fillenz, M. (1982). 
Acquisition and extinction of continuously and partially reinforced running in rats with lesions of the dorsal noradrenergic bundle. Behavior \& Brain Research, 5, 11-41.

Palacios, J. M., \& Wamsley, J. K. (1984). Catecholamine receptors. In A. Björklund, T. Hökfelt, \& M. I. Kuhar (Eds.), Handbook of chemical neuroanatomy (Vol. 3). Amsterdam: Elsevier.

PFISTER, H. P. (1979). The glucocorticosterone response to novelty as a psychological stressor. Physiology \& Behavior, 23, 649-652.

PISA, M., \& FibIGER, H. C. (1980). Noradrenaline and discrimination learning: Failure to support the attentional hypothesis. Society for $\mathrm{Neu}$ roscience Abstracts, 6, 724 .

Roberts, D. C. S., Price, M. T. C., \& Fibiger, H. C. (1976). The dorsal tegmental noradrenergic projection: An analysis of its role in maze learning. Journal of Comparative \& Physiological Psychology, 90, 363-372.

Segal, M., \& Bloom, F. E. (1976). The action of norepinephrine in the rat hippocampus. IV. The effect of locus coeruleus stimulation on evoked hippocampal unit activity. Brain Research, 107, 513-525.

Sessions, C. R., Kant, G. J., \& Kooв, G. F. (1976). Locus coeruleus lesions and learning in the rat. Physiology \& Behavior, 17, 853-859.

Shimizu, K. (1984). Effects of $\alpha^{1}$ and $\alpha^{2}$-adrenoceptors agonists and antagonists on ACTH secretion in intact and hypothalamic deafferentated rats. Japanese Journal of Pharmacology, 36, 23-33.

STONE, E. A. (1975). Stress and catecholamine. In A. J. Friedhoff (Ed.), Catecholamines and behavior (Vol. 2). New York: Plenum Press.

Tsuda, A., Tanaka, M., Kohno, Y., Nishikawa, T., Imori, K., NaKaGawa, R., HoAKI, Y., IDA, Y., \& NAGASAKI, N. (1982). Marked enhancement of noradrenaline turnover in extensive brain regions after activity stress in rats. Physiology \& Behavior, 29, 337-341.

Unnerstall, J. R., Kopajtic, T. A., \& Kuhar, M. J. (1984). Distribution of agonist binding sites in the rat and human central nervous system: Analysis of some functional, anatomic correlates of the pharmacological effects of clonidine and related adrenergic agents. Brain Research Reviews, 7, 69-101.

VELLEY, L. (1983). Rôle des systèmes aminergiques centraux dans la maitrise des conduites acquises. Thèse d'Etat, Université de Bordeaux I.
Velley, L., \& CARdo, B. (1977). A long-term effect of an early stimulation of the lateral hypothalamus on the acquisition and extinction of a food reinforced operant conditioning in the rat. Neuroscience Letters, 5, 221-226.

VELLEY, L., \& CARDO, B. (1979). Long-term improvement of learning after early electrical stimulation of some central nervous structures: Is the effect structure and age-dependent? Brain Research Bulletin, 4, 459-466.

Velley, L., Cardo, B., \& Bockaert, J. (1981). Modulation of rat brain adrenoceptor populations four weeks after stimulation of the nucleus locus coeruleus. Psychopharmacology, 74, 226-231.

Velley, L., Chassaing, J. M., \& Cardo, B. (1981). Learning improvement of appetitively or aversively reinforced light-dark discrimination and reversal four weeks after electrical stimulation of the lateral hypothalamus of the rat. Brain Research Bulletin, 6, 377-383.

Velley, L., KempF, E., \& CARDo, B. (1982). Locomotor activity of rats after stimulation of the nucleus locus coeruleus region or after lesion of the dorsal noradrenergic bundle. Psychopharmacology, 78, 239-244.

Velley, L., Nassif, S., KempF, E., \& Cardo, B. (1983). Enhancement of learning four weeks after stimulation of the nucleus locus coeruleus in the rat: Differential effects of dorsal noradrenergic bundle lesion and lesion of the locus coeruleus proper. Brain Research, 265, 273-282.

Weiss, J. M., Goodman, P. A., Losito, B. G., Corrigan, S., Charry, J. M., \& BAILEY, W. H. (1981). Behavioral depression produced by an uncontrollable stressor: Relationship to norepinephrine, dopamine and serotonin levels in various regions of the rat brain. Brain Research Reviews, 3, 167-205.

WoOdWARD, D. J., Moises, H. C., Waterhouse, B. D., Hoffer, B. J., \& FREEDMAN, R. (1979). Modulatory actions of norepinephrine in the central nervous system. Federation Proceedings, 38, 2109-2116.

(Manuscript received May 10, 1985; accepted for publication September 21, 1985.) 